\title{
Habitat selection according to the ability of animals to eat, digest and detoxify foods
}

\author{
Alan J. Duncan* and Iain J. Gordon \\ Macaulay Land Use Research Institute, Craigiebuckler, Aberdeen AB15 8QH
}

\begin{abstract}
Large herbivores play a major role in shaping vegetation community dynamics through selective consumption of particular plants and plant communities. An understanding of the factors influencing diet selection at the level of individual bites ('bite scale') is important for prediction of the impact of herbivores on vegetation at the habitat scale. Bite-scale diet selection represents an integration of the twin goals of maximizing nutrient intake and minimizing toxin intake. Recent research with ruminants in pen-fed situations has shown that animals are able to make choices between artificial foods that maximize growth and other production variables. The role of postingestive feedback as an important mechanism for allowing animals to assess the nutritional quality of particular foods, and so select optimal diets, has been recognized in a number of recent experiments. Our understanding of the role of toxin intake minimization in diet selection decisions is more rudimentary. An important advance in the last decade has been the acknowledgement of the role of post-ingestive feedback and learning as a mechanism for avoidance of dietary toxicity. Further research is required to assess the importance of these processes in relation to free-grazing animals. The extent to which an understanding of bite-scale diet selection can be used to predict habitat utilization is not well understood. At the habitat scale additional factors such as predator avoidance, social constraints, avoidance of parasitism and microclimatic effects have an important influence on foraging decisions. Future research needs to focus on developing a quantitative understanding of such decisions at the habitat scale.
\end{abstract}

Diet selection: Habitat selection: Herbivore: Post-ingestive feedback

Large herbivores are major drivers of ecosystem function and dynamics in many terrestrial biomes. Through grazing, trampling, defecation and urination they affect nutrient flows, vegetation community dynamics and the responses of associated fauna. In turn, ecosystem characteristics such as composition, productivity and distribution of resources determine the nutrition of individual herbivores and the dynamics of herbivore populations. Consequently, knowledge of the foraging behaviour and habitat use of herbivores is of primary importance in determining the relationships between individual animal and population performance, and between herbivorous animals and their vegetation resources. Only through the development of this understanding can objective guidance for the sustainable management of natural resources be given.

Herbivores foraging in heterogeneous environments focus their foraging pressure on particular plant communities. Thus, their impact on the vegetation is distributed across the foraging environment in a non-uniform way. A range of factors can influence the choice of habitats by large herbivores, and it is important to understand these influences in order to arrive at a predictive means of assessing how herbivores will distribute their foraging effort within a given environment.

The pattern of habitat selection varies according to factors such as season and species. For example, sheep show marked seasonal patterns of plant community selection (Hunter, 1962). Similarly, different herbivore species utilize different plant communities to different extents. For example, in a recent comparative study (Fraser \& Gordon, 1997), utilization of different plant communities by goats (Capra hircus), red deer (Cervus elaphus) and the South American camelid, the guanaco (Guanaco guanaco) was studied. Differences in patterns of utilization of different plant species within habitats were apparent with, for example, red deer showing higher utilization of Calluna vulgaris than either goats or camelids. Thus, whilst it is possible to describe the pattern of habitat utilization that we observe in 
particular circumstances, in order to move towards a predictive understanding of foraging patterns, an understanding of the mechanisms which underlie the observed pattern of utilization is needed.

In seeking to understand habitat selection, issues of scale are important. Foraging decisions are made at a range of scales from the bite-scale scale to the regional scale. A number of different systems for describing the hierarchy of scales at which foraging behaviour can be viewed have been described (Senft et al. 1987; Stuth, 1991; Bailey et al. 1996). As pointed out in these reviews, patterns of foraging at the level of landscape represent, to a certain extent, an integration of decisions made at smaller scales. To understand the patterns of resource use at larger scales (habitat selection), there is a need, therefore, to consider influences on small-scale foraging decisions, i.e. diet selection. To set the discussion in the present paper in context, 'habitat' is defined as being equivalent to 'feeding site' (Bailey et al. 1996), being a collection of patches in a contiguous spatial area that animals graze during a foraging bout. 'Diet selection', on the other hand, would be at the spatial level of 'bite' or 'feeding station' as outlined by Bailey et al. (1996).

Factors influencing diet selection have been extensively studied, and are the subject of recent reviews (Milne, 1991; Hanley, 1997). From simple observation it is clear that freeranging herbivores select a diet which is richer in nutrients and which contains lower concentrations of plant secondary compounds than the average available plant material (Murden \& Risenhoover, 1993). In crude terms diet selection can be viewed as the process by which herbivores balance the twin goals of nutrient maximization and toxin minimization. Our understanding of the physiological basis of diet selection decisions has been advanced, particularly in the last decade, by research with pen-fed agricultural animals. Some of this work will be reviewed here, and the extent to which conclusions from these studies are relevant to free-ranging herbivores will be considered.

\section{Diet selection: nutrient maximization}

Optimal foraging models predict that foraging animals should aim to maximize their rate of intake of the nutrient most limiting to growth and/or reproduction. Intake rate maximization is constrained by both the nutritional quality of available food items and by their abundance. This tradeoff between quality and quantity is, therefore, a key factor in determining the diet which different herbivores ultimately select, and is responsible, in particular, for the variation in optimal diet selection solutions for different sizes of herbivores (Gordon, 1989; Illius \& Gordon, 1992).

Trade-offs between quality and quantity of available herbage may lead herbivores to select diets of intermediate quality in order to maximize their overall rate of nutrient assimilation (Wilmshurst et al. 1995). However, in circumstances where quantity is not a constraint, herbivores should aim to select food items with maximal concentrations of the nutrients most limiting to growth and/or reproduction. There has been some debate as to which the key nutrient for maximization is in different circumstances. Candidates include N (or protein; Mattson, 1980; Kronberg \& Malechek, 1997), carbohydrates (or energy; Belovsky,
1984, Murray, 1991; Stuth, 1991; Wallis de Vries \& Schippers, 1994) and minerals (Belovsky, 1978). Some studies in the ecological literature are naive in their consideration of protein and energy as being discrete nutrients for ruminant herbivores. There has been a failure to recognize that in nutrient-poor systems, carbohydrate digestion is dependent on an adequate supply of $\mathrm{N}$ to the rumen microbial population to allow optimal microbial growth.

Recently, there has been a marked increase in interest in diet selection within the agricultural and nutritional disciplines, bringing with it a notable increase in the nutritional sophistication of research on diet selection. Work with rats and pigs has shown that these species select a diet which matches their nutritional requirements (Rozin, 1976; Kyriazakis \& Emmans, 1991). The idea that animals display 'nutritional wisdom' has been extended into ruminant research; for example, in one experiment sheep given a choice between foods differing in crude protein $(\mathrm{N} \times 6.25)$ content selected a diet which led to maximal growth rates (Kyriazakis \& Oldham, 1993). Recent work with dairy cows has also shown that animals are capable of making longterm diet choices which maximize milk yield (Tolkamp et al. 1998). Experiments by the same authors also indicate that dairy cows select diets which avoid excessive rumendegradable $\mathrm{N}$. The area of nutritional wisdom is complicated in ruminants by the interaction between energy and $\mathrm{N}$ metabolism in the rumen. Thus, selection of a high-protein diet for protein-limited animals is not necessarily the best solution if there is inadequate carbohydrate as an energy source for rumen micro-organisms. This situation has led to the interesting hypothesis that ruminants select a diet which favours optimal conditions for rumen fermentation. This hypothesis has been tested by manipulating rumen $\mathrm{pH}$ through acid and alkali infusion, but with inconclusive results (Cooper et al. 1995).

This recent work on nutritional wisdom in pen-fed situations has been useful in bringing an understanding of ruminant nutrition to the question of diet selection. In some studies, however, the diet selected by experimental animals has not supported the nutritional wisdom hypothesis (Forbes $\&$ Kyriazakis, 1995). This finding may be due, in part, to the fact that agricultural animals have not been selected for their ability to select an optimal diet from pelleted alternatives. This situation leads to the question of how nutritional wisdom is achieved. The assumption in the earlier work was that ruminants learn about the nutritional properties of their foods through post-ingestive feedback. The experiments described previously involved a period of training during which animals were given the opportunity to experience each food item in isolation for feeding bouts of 1 or $2 \mathrm{~d}$ before being offered choices. The idea that ruminants learn to select appropriate diets by learning to associate sensory cues with post-ingestive consequences has gained credence through a number of recent infusion experiments. It has been shown, for example, that sheep offered flavoured diets while simultaneously being intraruminally infused with urea or casein will subsequently show a preference for the food paired with the infusate (Villalba \& Provenza, 1997). A similar phenomenon has been demonstrated for energy sources where preferences for flavoured feeds have been enhanced following previous pairing with sugar (Ralphs 
et al. 1995) or volatile fatty acid infusions (Villalba \& Provenza, 1996). However, some caution is required in invoking positive post-ingestive feedback as the basis for diet learning in free-grazing systems; indoor feeding experiments on nutritional wisdom and positive post-ingestive feedback involve simple food choices where the animal is given individual foods for feeding bouts lasting $1 \mathrm{~d}$ or more. This situation does not mimic the free-grazing situation, where there is little evidence that animals restrict their diet to individual food items for any length of time.

The assumption in much of the ecological literature is that food choices are made not on the basis of learned responses to the physiological consequences of consuming particular food items, but on the basis of simple sensory cues which provide immediate information about the nutritional properties of different plants (Bazely, 1990; Edwards et al. 1997). There is some evidence that previous experience can influence the diet selected by sheep (Langlands, 1969), but this finding may be as much to do with experience of harvesting particular plants than with experience of their nutritional properties.

There have been few rigorous tests of nutritional wisdom in free-grazing situations. In one experiment with sheep grazing Calluna vulgaris (Duncan et al. 1994a) the $\mathrm{N}$ demand of the experimental animals was manipulated by offering them isoenergetic supplements differing in crude protein content. The hypothesis was that animals with inadequate supplies of $\mathrm{N}$ in the rumen (barley supplement) would seek out a more N-rich diet than those with adequate $\mathrm{N}$ supplementation (soyabean supplement). The sheep were allowed to graze a Calluna vulgaris moorland where N-rich patches had been created by fertilizing with $\mathrm{NH}_{4} \mathrm{NO}_{3}$. Sheep showed a dramatic preference for $\mathrm{N}$-enriched patches despite no discernible difference in the morphology of fertilized and unfertilized patches. However, the supplementation regimen had no impact on diet selection. Measurement of rumen $\mathrm{NH}_{3}$ concentrations suggested that even barley-supplemented animals had reasonably high concentrations of $\mathrm{N}$ in their rumens, possibly due to more efficient urea recycling. The experiment clearly demonstrated that ruminants show a strong preference for nutrient-rich food patches. The question of how, and whether, they match their diet selection to their requirements remains unclear. It may be that in most natural scenarios there is no need to limit the quality of the diet selected, since food plants with excessive concentrations of nutrients are never encountered. There is a need for further studies on nutritional wisdom in relation to free-grazing animals.

\section{Diet selection: toxin minimization}

As well as maximizing nutrient intake, herbivores need to minimize their ingestion of the wide range of toxins found in food plants. Quantitative understanding of this process is more rudimentary than that in the area of nutrient maximization. Indeed, the influence of secondary compounds on diet selection is routinely employed as an explanation for the variation in diet selection that cannot be accounted for on the basis of nutrient maximization (Belovsky, 1981; Angerbjorn \& Pehrson, 1987). The crude state of our understanding of the role of secondary compounds in food choice is partly related to the fact that the range of chemical compounds to be considered is diverse, with numerous different groups of secondary plant compounds existing in nature. In addition, the effects of secondary compounds on fitness are unpredictable and difficult to measure. Furthermore, nutritive value and secondary compound concentrations often show an inverse relationship in plants, making it difficult to distinguish between their relative effects on food choice. A number of different experimental approaches have been employed to investigate the role of secondary plant compounds in diet selection. One approach is to incorporate the isolated toxin into artificial feeds and to investigate the impact on food choice (Elliot \& Loudon, 1987). This approach has the disadvantage that isolating secondary compounds from their natural location within the plant may radically alter their physiological effects. At the other extreme, observational approaches have been adopted where natural variation in concentrations of secondary compounds in natural foraging environments has been related to utilization of food plants by free-grazing animals (Cooper et al. 1988; Owen-Smith, 1994). The problem here is one of attributing cause and effect with concentrations of a large range of chemical compounds varying simultaneously, making it difficult to attribute observed preferences to particular compounds. Experiments using intact food plants in controlled circumstances have provided some convincing demonstrations of the impact of individual secondary compounds on food selection (Hjalten \& Palo, 1992; Duncan et al. 1994b; Rangen et al. 1994; Tixier et al. 1997) and further studies of this nature would be helpful.

In common with research on diet selection in the area of nutrient maximization, there has been much recent interest in the idea that ruminants learn to avoid plant secondary compounds through learning to associate their postingestive consequences with sensory cues. Research on conditioned food aversions in ruminants follows similar work with rats, which are particularly adept at avoiding toxic foods (Rozin, 1976; Zahorik \& Houpt, 1981). The majority of these experiments have employed artificial aversive stimuli, such as $\mathrm{LiCl}$ and apomorphine, which induce nausea. The general protocol for these experiments typically involves feeding novel foods to animals while simultaneously applying the aversive stimulus. These experiments have demonstrated the development of strong aversions to foods paired with aversive stimuli (Ralphs, 1992), and have shown that the strength of the aversion is related to the magnitude of the aversive stimulus (du Toit et al. 1991). More recently, it has been shown that herbivores can develop mild conditioned food aversions to aversive stimuli which they would naturally encounter in food plants (Kyriazakis et al. 1997). The original context for much of the work on conditioned food aversions was as a management tool to train livestock to avoid toxic plants (Ralphs, 1992). More recently there has been some speculation that conditioned food aversions represent an important mechanism by which ruminants avoid toxicity in freegrazing situations (Provenza et al. 1992; Provenza, 1995). Experiments to date have predominantly been conducted in artificial conditions in which animals are given simple 
choices between artificial feeds following a period of conditioning to artificial aversive stimuli. There is a substantial gulf between this scenario and the free-grazing situation where animals select a wide range of plants within a single feeding bout and where the aversive stimuli do not necessarily stimulate the emetic system. Thus, further experimentation is required before invoking conditioned food aversions as an important influence on toxin avoidance in the field.

One of the difficulties in attributing diet selection decisions to the presence of secondary compounds in food plants is that physiological responses of herbivores to secondary compounds are highly variable. This variability arises because herbivores have efficient mechanisms for minimizing the toxic effects of secondary compounds through their detoxification and elimination in a benign form. Detoxification can occur at a number of stages following ingestion. First, there has been some speculation that tannins in particular can lose their biological activity in the mouth by forming complexes with salivary tannin-binding proteins. Such proteins have been identified in rats (Mehansho et al. 1987), although evidence for their importance in ruminants is less convincing (Austin et al. 1989). There is some evidence that different herbivore species have tannin-binding proteins with particular affinity for the tannins they are likely to encounter in their food plants (Hagerman \& Robbins, 1993). Following ingestion, the rumen represents an important site for biotransformation under the action of rumen microbes (Jones, 1981; Dickinson et al. 1988; Anderson et al. 1993). Following absorption there is further potential for detoxification in the tissues under the action of phase I and phase II xenobioticmetabolizing enzymes (Watkins \& Klaassen, 1986). Both rumen metabolism and tissue level detoxification are highly plastic processes, responding to the presence of substrates with substantial changes in levels of activity. There is thus much potential for inter-animal variability in susceptibility to plant secondary compounds, depending on the degree of physiological adaptation to particular compounds. There may also be inherent differences between species in metabolic detoxification pathways, and these differences may lead to inter-species variation in susceptibility to secondary compounds (Wachenheim et al. 1992). Species variation in the tannin-binding efficiency of salivary tannin-binding proteins to different classes of tannins may partially explain the different susceptibilities of herbivore species to the effects of tannins from different sources (Hagerman \& Robbins, 1993). Despite the considerable animal variation in susceptibility to secondary compounds, there has been little research on its possible influence on diet selection. Kronberg \& Walker (1993) showed species differences in the metabolism of the toxic principle in leafy spurge (Euphorbia esula) and suggested that this finding might account for variation in preference for the plant by sheep and goats. In recent work it has been shown that the rate of degradation of oxalic acid in the rumen of goats influences the proportion of oxalic acid-containing plants that goats consume as part of their diet (Duncan et al. 1998).

\section{Habitat selection}

Factors influencing food selection by herbivores at the bite scale have been described earlier. It has been argued that diet selection decisions can be interpreted as outcomes of the twin goals of nutrient maximization and toxin minimization. The extent to which understanding of foraging decisions made at the bite scale can be amplified in order to predict foraging patterns at the higher habitat scale must now be considered. To what extent can habitat selection be viewed as an integration of numerous bite-scale decisions? As pointed out by Senft et al. (1987), the closeness of the relationship between resource productivity and herbivore distribution diminishes with increasing scale. This situation is due to the increasing influence of factors other than purely nutritional considerations in determining foraging patterns. In the real world the herbivore is faced with a series of tradeoffs about which habitat to choose. Some habitats may offer more in the way of food for the animal, but at the same time they may present more in the way of risk. For example, the degree of exposure to the weather or predators may be greater.

There has been much work on the relationship between habitat choice and food benefits and predation risk in small mammals and birds (Lima \& Dill, 1990). However, little work has been done on the way in which predation risk can influence where a herbivore chooses to feed (Cowlishaw, 1997). One of the factors influencing sexual segregation in habitat use in ruminants is thought to be differences in the susceptibility to predation in males as compared with females and their young (Main et al. 1996). If males are less prone to predation, their distribution is more closely related to the distribution of food in the environment, whereas the distribution of females is related to the availability of habitats which offer cover or escape terrain. Whilst this behaviour is frequently observed in wild species, there is now some evidence for the possible influence of predation on the feeding behaviour of sheep. Sheep penned in paddocks in group sizes of less than four had lower intake rates than those in large group sizes (Penning et al. 1993). The authors attributed this finding to the possibility that the sheep in smaller group sizes were more vigilant as they viewed the potential predation risk as being greater. Thus far there has been no explicit test of the effects of perceived predation risk on the foraging behaviour of domestic species, although this work has been done in other groups of mammals and birds (Lima \& Dill, 1990).

On the other hand, there is increasing evidence from studies on domestic species that avoidance of parasitism can impinge on the foraging behaviour of herbivores. For example, sheep avoided utilizing patches of vegetation which had higher faecal burdens than uncontaminated patches (Cooper, 1997). Parasitic helminth larvae were applied to pastures either in isolation or together with faecal material. The results showed that sheep avoided infected patches when larvae were applied together with their faeces matrix. This finding may have been due simply to avoidance of faeces per se as can be seen by the fact that the sheep avoided the faeces from parasitized and non-parasitized animals to the 
same extent. Interestingly, infected and non-infected animals avoided infected pasture to different degrees, with non-infected animals showing less avoidance behaviour than infected animals. In nutrient-poor systems this behaviour may result in herbivores trading off the costs of ingesting infective parasite larvae with the benefit of consuming the nutritious grass which is associated with nutrients leached from faeces. Further studies have shown that sheep will avoid the consumption of grass infected with larvae, even though it may offer them higher intake rates (Hutchings et al. 1999). This is particularly the case for animals which are naive to parasites. Furthermore, animals that are hungry are more likely to opt for intake rate at the expense of larval ingestion. Whilst these studies are in their infancy, they demonstrate that domestic animals, at least, assess the costs as well as the benefits of their foraging decisions.

Although there have been studies on the dispersion of groups of herbivores and the interactions that take place between individuals (Arnold \& Maller, 1985), there is a lack of information about how social behaviour may affect foraging strategy, particularly in heterogeneous ecosystems. Social interactions may limit the efficiency with which herbivores satisfy their appetite drive, either through competitive interactions or the need to maintain cohesive social groups. Competitive interactions may also influence utilization of scarce resources. For example, in an experiment with sheep, different age classes of Scottish Blackface sheep utilized feed blocks to markedly different extents (Lawrence \& Wood-Gush, 1988). This finding was attributed to the formation of cohesive social groups by juvenile animals which were uninfluenced by movements of mature ewes to feed blocks. Within groups the position in the social hierarchy can also affect the rate of food ingestion. In red deer subordinates had lower feeding rates than did dominants when in close proximity (Thouless \& Guinness, 1986). This finding was attributed to the possibility that subordinates were alert to movement of the dominants, and continuously moved out of their way to avoid conflict. As yet there is no published study which demonstrates that position in the social hierarchy affects an individual's access to food patches or habitats of different quality.

Herbivores may also be influenced in their choice of habitat by the microclimate offered by various habitats (Senft et al. 1985). The extent to which animals are influenced by microclimate is likely to depend on their susceptibility to extreme conditions. Thus, sheep that are relatively well insulated and are able to stand severe conditions without energetic cost (Blaxter, 1977) do not appear to be unduly influenced by the need to seek shelter unless they have juveniles at foot (Alexander et al. 1979). Deer, on the other hand, appear to respond to topography and adjust their choice of foraging locations accordingly (Staines, 1976). In hot climates, on the other hand, the insulatory capacity of wool for sheep may increase heat stress and lead to their seeking out habitats which offer shelter at the expense of time they could spend in food-rich habitats (Stafford Smith et al. 1985)

One of the ultimate goals of the research on intake and diet selection of herbivores in extensive systems is the development of a predictive understanding of habitat utilization to help land managers assess the consequences of their management decisions on animal production and the impact on the vegetation resource. Research on diet selection at the bite scale has progressed sufficiently to allow good predictions of diet choice to be made. The focus in future research needs to translate understanding of the bite-scale decision-making process to higher scales, and to further develop our understanding of the additional factors which influence foraging decisions at the habitat scale. This process has already begun with the development of decision support tools which incorporate quantitative and qualitative rules and relationships derived from foraging experiments, along with expert knowledge, to provide comprehensive computer-based programmes relevant to land managers (Buckland et al. 1998). Further developments of this type will help to integrate our current knowledge of foraging behaviour into useful frameworks for land managers.

\section{Acknowledgements}

Thanks to Dr John A. Milne for helpful comments on a draft of this paper. The authors are supported by funding from the Scottish Office Agriculture, Environment and Fisheries Department.

\section{References}

Alexander G, Lynch JJ \& Mottershead BE (1979) Use of shelter and selection of lambing sites by shorn and unshorn ewes in paddocks with closely or widely spaced shelters. Applied Animal Ethology 5, 51-69.

Anderson RC, Rasmussen MA \& Allison MJ (1993) Metabolism of the plant toxins nitropropionic acid and nitropropanol by ruminal microorganisms. Applied and Environmental Microbiology 59, 3056-3061.

Angerbjorn A \& Pehrson A (1987) Factors influencing winter food choice by mountain hares (Lepus timidus L.) on Swedish coastal islands. Canadian Journal of Zoology 65, 2163-2167.

Arnold GW \& Maller RA (1985) An analysis of factors influencing spatial distribution in flocks of grazing sheep. Applied Animal Behaviour Science 14, 173-189.

Austin PJ, Suchar LA, Robbins CT \& Hagerman AE (1989) Tannin-binding proteins in saliva of deer and their absence in saliva of sheep and cattle. Journal of Chemical Ecology 15, 1335-1347.

Bailey DW, Gross JE, Laca EA, Rittenhouse LR, Coughenour MB, Swift DM \& Sims PL (1996) Mechanisms that result in large herbivore grazing distribution patterns. Journal of Range Management 49, 386-400.

Bazely DR (1990) Rules and cues used by sheep foraging in monocultures. In Behavioural Mechanisms of Food Selection, pp. 343-368 [RN Hughes, editor]. Berlin and Heidelberg: Springer-Verlag.

Belovsky GE (1978) Diet optimization in a generalist herbivore: the moose. Theoretical Population Biology 14, 105-134.

Belovsky GE (1981) Food plant selection by a generalist herbivore: the moose. Ecology 62, 1020-1030.

Belovsky GE (1984) Herbivore optimal foraging: a comparative test of three models. American Naturalist 124, 97-115.

Blaxter KL (1977) Environmental factors and their influence on the nutrition of farm livestock. In Nutrition and the Climatic Environment, pp. 1-16 [W Haresign, H Swan and D Lewis, editors]. London: Butterworths. 
Buckland ST, Trenkel VM, Elston DA, Partridge LW \& Gordon IJ (1998) A decision support system for deer managers in Scotland. In Population Ecology, Management and Welfare of Deer pp. 82-87 [CR Goldspink, S King and RJ Putman, editors]. Manchester: Manchester Metropolitan University.

Cooper J (1997) The behavioural control of helminth infection in sheep. PhD Thesis, University of Edinburgh.

Cooper SDB, Kyriazakis I \& Nolan JV (1995) Diet selection in sheep: the role of the rumen environment in the selection of a diet from two feeds that differ in their energy density. British Journal of Nutrition 74, 39-54.

Cooper SM, Owen-Smith N \& Bryant JP (1988) Foliage acceptability to browsing ruminants in relation to seasonal changes in leaf chemistry of woody plants in a South African savanna. Oecologia 75, 336-342.

Cowlishaw G (1997) Trade-offs between foraging and predation risk determine habitat use in a desert baboon population. Animal Behaviour 53, 667-686.

Dickinson JM, Smith GR, Randel RD \& Pemberton IJ (1988) In vitro metabolism of Formononetin and Biochanin A in bovine rumen fluid. Journal of Animal Science 66, 1969-1973.

Duncan AJ, Frutos P \& Kyriazakis I (1998) Conditioned food aversions to oxalic acid in the food plants of sheep and goats. In Toxic Plants and Other Natural Toxicants, pp. 169-173 [T Garland and AC Barr, editors]. New York: CAB International.

Duncan AJ, Hartley SE \& Iason GR (1994a) Fine scale discrimination of forage quality by sheep offered a soya-bean meal or barley supplement while grazing a nitrogen-fertilized heather (Calluna vulgaris) mosaic. Journal of Agricultural Science, Cambridge 123, 363-370.

Duncan AJ, Hartley SE \& Iason GR (1994b) The effect of monoterpene concentrations in Sitka spruce (Picea sitchensis) on the browsing behaviour of red deer (Cervus elaphus). Canadian Journal of Zoology 72, 1715-1720.

du Toit JT, Provenza FD \& Nastis A (1991) Conditioned taste aversions: how sick must a ruminant get before it learns about toxicity in foods. Applied Animal Behaviour Science 30, 35-46.

Edwards GR, Newman JA, Parsons AJ \& Krebs JR (1997) Use of cues by grazing animals to locate food patches: an example with sheep. Applied Animal Behaviour Science 51, 59-68.

Elliot S \& Loudon A (1987) Effects of monoterpene odors on food selection by red deer calves. Journal of Chemical Ecology 13, 1343-1349.

Forbes JM \& Kyriazakis I (1995) Food preferences in farm animals: why don't they always choose wisely? Proceedings of the Nutrition Society 54, 429-440.

Fraser MD \& Gordon IJ (1997) The diet of goats, red deer and South American camelids feeding on three contrasting Scottish upland vegetation communities. Journal of Applied Ecology 34, 668-686.

Gordon IJ (1989) Vegetation community selection by ungulates on the Isle of Rhum. III. Determinants of vegetation community selection. Journal of Applied Ecology 26, 65-79.

Hagerman AE \& Robbins CT (1993) Specificity of tannin-binding salivary proteins relative to diet selection by mammals. Canadian Journal of Zoology 71, 628-633.

Hanley TA (1997) A nutritional view of understanding and complexity in the problem of diet selection by deer (Cervidae). Oikos 79, 209-218.

Hjalten J \& Palo T (1992) Selection of deciduous trees by free ranging voles and hares in relation to plant chemistry. Oikos $\mathbf{6 3}$, 477-484.

Hunter RF (1962) Hill sheep and their pasture: A study of sheepgrazing in south-east Scotland. Journal of Ecology 50, 651-680.

Hutchings MR, Kyriazakis I, Anderson DH, Gordon IJ \& Coop RL (1999) Trade-offs between nutrient intake and faecal avoidance in herbivore foraging decisions: the effect of parasite status. Journal of Animal Ecology 68, 310-323.

Illius AW \& Gordon IJ (1992) Modelling the nutritional ecology of ungulate herbivores: evolution of body size and competitive interactions. Oecologia 89, 428-434.

Jones RJ (1981) Does ruminal metabolism of mimosine explain the absence of Leucaena toxicity in Hawaii. Australian Veterinary Journal 57, 55-56.

Kronberg SL \& Malechek JC (1997) Relationships between nutrition and foraging behavior of free-ranging sheep and goats. Journal of Animal Science 75, 1756-1763.

Kronberg SL \& Walker JW (1993) Ruminal metabolism of leafy spurge in sheep and goats - A potential explanation for differential foraging on spurge by sheep, goats, and cattle. Journal of Chemical Ecology 19, 2007-2017.

Kyriazakis I \& Emmans GC (1991) Diet selection in pigs: dietary choices made by growing pigs following a period of underfeeding with protein. Animal Production 52, 337-346.

Kyriazakis I \& Oldham JD (1993) Diet selection in sheep: the ability of growing lambs to select a diet that meets their crude protein (nitrogen $\times 6.25$ ) requirements. British Journal of Nutrition 69, 617-629.

Kyriazakis I, Papachristou TG, Duncan AJ \& Gordon IJ (1997) Mild conditioned food aversions developed by sheep towards flavours associated with plant secondary compounds. Journal of Chemical Ecology 23, 727-746.

Langlands JP (1969) Studies on the nutritive value of the diet selected by grazing sheep. IV. Variation in the diet selected by sheep differing in age, breed, sex, strain and previous history. Animal Production 11, 369-378.

Lawrence AB \& Wood-Gush DGM (1988) Influence of social behaviour on utilization of supplemental feedblocks by Scottish hill sheep. Animal Production 46, 203-212.

Lima SL \& Dill DM (1990) Behavioural decisions made under the risk of predation: a review and prospectus. Canadian Journal of Zoology 68, 619-640.

Main MB, Weckerly FW \& Bleich VC (1996) Sexual segregation in ungulates: New directions for research. Journal of Mammalogy 77, 449-461.

Mattson WJ (1980) Herbivory in relation to plant nitrogen content. Annual Review of Ecology and Systematics 11, 119-161.

Mehansho H, Butler LG \& Carlson DM (1987) Dietary tannins and salivary proteins: interactions, induction and defense mechanisms. Annual Review of Nutrition 7, 423-440.

Milne JA (1991) Diet selection by grazing animals. Proceedings of the Nutrition Society 50, 77-85.

Murden SB \& Risenhoover KL (1993) Effects of habitat enrichment on patterns of diet selection. Ecological Applications 3, 497-505.

Murray MG (1991) Maximising energy retention in grazing ruminants. Journal of Animal Ecology 60, 1029-1045.

Owen-Smith N (1994) Foraging responses of kudus to seasonal changes in food resources: Elasticity in constraints. Ecology 75, 1050-1062.

Penning PD, Parsons AJ, Newman JA, Orr RJ \& Harvey A (1993) The effects of group size on grazing time in sheep. Applied Animal Behaviour Science 37, 101-109.

Provenza FD (1995) Postingestive feedback as an elementary determinant of food preference and intake in ruminants. Journal of Range Management 48, 2-17.

Provenza FD, Pfister JA \& Cheney CD (1992) Mechanisms of learning in diet selection with reference to phytotoxicosis in herbivores. Journal of Range Management 45, 36-45.

Ralphs MH (1992) Conditioned food aversion: training livestock to avoid eating poisonous plants. Journal of Range Management 45, 46-51. 
Ralphs MH, Provenza FD, Wiedmeier WD \& Bunderson FB (1995) Effects of energy source and food flavor on conditioned preferences in sheep. Journal of Animal Science 73, 1651-1657.

Rangen SA, Hawley AWL \& Hudson RJ (1994) Relationship of snowshoe hare feeding preferences to nutrient and tannin content of four conifers. Canadian Journal of Forest Research 24, 240-245.

Rozin P (1976) The selection of foods by rats, humans and other animals. In Advances in the Study of Behaviour, vol. 6, pp. 2176 [JS Rosenblatt, RA Hinde, E Shaw and C Beer, editors]. New York: Academic Press.

Senft RL, Coughenour MB, Bailey DW, Rittenhouse LR, Sala OE \& Swift DM (1987) Large herbivore foraging and ecological hierarchies. Bioscience 37, 789-799.

Senft RL, Rittenhouse LR \& Woodmansee RG (1985) Factors influencing patterns of cattle grazing behavior on shortgrass steppe. Journal of Range Management 38, 82-87.

Stafford Smith DM, Noble IR \& Jones GK (1985) A heat balance model for sheep and its use to predict shade-seeking behaviour in hot conditions. Journal of Animal Ecology 22, 753-774.

Staines BW (1976) The use of natural shelter by red deer in relation to weather in north-east Scotland. Journal of Zoology 180, 1-8.

Stuth JW (1991) Foraging behavior. In Grazing Management: An Ecological Perspective, pp. 65-83 [RK Heidschmidt and JW Stuth, editors]. Portland, OR: Timber Press.

Thouless CR \& Guinness FE (1986) Conflict between red deer hinds: the winner always wins. Animal Behaviour 34, 1166-1171.

Tixier H, Duncan P, Scehovic J, Yani A, Gleizes M \& Lila M (1997) Food selection by European roe deer (Capreolus capreolus): effects of plant chemistry, and consequences for the nutritional value of their diets. Journal of Zoology 242, 229-245.

Tolkamp BJ, Dewhurst RJ, Friggens NC, Kyriazakis I, Veerkamp RF \& Oldham JD (1998) Diet choice by dairy cows. 1. Selection of feed protein content during the first half of lactation. Journal of Dairy Science 81, 2657-2669.

Villalba JJ \& Provenza FD (1996) Preference for flavored wheatstraw by lambs conditioned with intraruminal administrations of sodium propionate. Journal of Animal Science 74, 2362-2368.

Villalba JJ \& Provenza FD (1997) Preference for flavoured foods by lambs conditioned with intraruminal administration of nitrogen. British Journal of Nutrition 78, 545-561.

Wachenheim DE, Blythe LL \& Craig AM (1992) Characterization of rumen bacterial pyrrolizidine alkaloid biotransformation in ruminants of various species. Veterinary and Human Toxicology 34, 513-517.

Wallis de Vries MF \& Schippers P (1994) Foraging in a landscape mosaic - selection for energy and minerals in free-ranging cattle. Oecologia 100, 107-117.

Watkins JBI \& Klaassen CD (1986) Xenobiotic biotransformation in livestock: comparison to other species commonly used in toxicity testing. Journal of Animal Science 63, 933-942.

Wilmshurst JF, Fryxell JM \& Hudson RJ (1995) Forage quality and patch choice by wapiti (Cervus elaphus). Behavioral Ecology 6, 209-217.

Zahorik DM \& Houpt KA (1981) Species differences in feeding strategies, food hazards and the ability to learn food aversions. In Foraging Behaviour, pp. 289-310 [AC Kamil and TD Sargent, editors]. New York: Garland. 